\title{
UGT1A1, SLCO1B1, and SLCO1B3 polymorphisms vs. neonatal hyperbilirubinemia: is there an association?
}

\author{
Laura Alencastro de Azevedo ${ }^{1-3}$, Themis Reverbel da Silveira ${ }^{1,2}$, Clarissa Gutierrez Carvalho', Simone Martins de Castro ${ }^{3}$, \\ Roberto Giugliani $\mathrm{i}^{1,4}$ and Ursula Matte ${ }^{1,4}$
}

BACKGROUND: Jaundice is a physiological phenomenon; however, severe hyperbilirubinemia occurs in only 5 to $6 \%$ of the healthy newborn population. It has been suggested that genetic variation could enhance the risk of hyperbilirubinemia when coexpressed with other icterogenic conditions.

METHODS: The study included newborns with a gestational age of greater than $35 \mathrm{wk}$ and weights greater than 2,000 g with indications for phototherapy. The polymorphisms from UGT1A1 (rs8175347), SLCO1B1 (rs4149056 and rs2306283), and SLCO1B3 (rs17680137 and rs2117032) were analyzed by capillary electrophoresis and hydrolysis probes.

RESULTS: A total of 167 hyperbilirubinemic infants and 247 control subjects were enrolled. The gender, ABO incompatibility, birth weight, and gestational age differed between the groups, but the allelic and genotypic frequency of the polymorphisms from SLCO1B genes did not. In logistic regression, the $A B O$ incompatibility, gestational age, and polymorphic T allele of rs2117032 remained in the model. The presence of this polymorphism seemed to provide protection from hyperbilirubinemia. The individuals who were homozygous for the $G$ allele of rs2306283 and who were glucose 6-phosphatedehydrogenase deficient were more frequent among the cases.

CONCLUSION: Although genetic variation accounts for a good part of this condition, the association between different polymorphisms and environmental factors has yet to be explained.

aundice is a physiological phenomenon that occurs in $60 \%$ of healthy newborns and nearly all preterm infants. However, severe hyperbilirubinemia (total serum bilirubin levels above the 95th percentile for age in hours) occurs in only 5 to $6 \%$ of the healthy newborn population (1). Some of the risk factors for hyperbilirubinemia include the following: hemolytic conditions, poor caloric intake, cephalohematoma or significant bruising, exclusive breastfeeding, weight loss, East Asian race, and male gender (2). Newborns must be monitored to identify those who might develop severe hyperbilirubinemia due to toxicity of bilirubin, and, in some cases, acute bilirubin encephalopathy, which might evolve to kernicterus.

It has been suggested that genetic variation could enhance the risk of hyperbilirubinemia when coexpressed with other icterogenic conditions (3). The rs8175347 polymorphism from the promoter region of the uridine-diphosphoglucuronosyl transferase 1A1 (UGT1A1) gene is described as a major cause of Gilbert's syndrome (4), which is characterized by an increase of total serum bilirubin as a result of poor enzymatic conjugation by glucuronosyltransferase (EC 2.4.1.17). TA sequences in the promoter region vary in length from 5 to 8 repeats, and the $\mathrm{TA}_{7}$ and $\mathrm{TA}_{8}$ alleles are primarily responsible for the total serum bilirubin increase and could contribute to neonatal hyperbilirubinemia (5). The variant $\mathrm{TA}_{5}$ is associated with an increase in UGT1A1 transcription; whereas $\mathrm{TA}_{8}$ is associated with reduced transcription (6). Both of these alleles are rare and usually found in people of African descent (6). SLCO1B1, the gene encoding the hepatic solute carrier organic anion transporter 1B1, a putative bilirubin transporter, could also be associated with an increased predisposition to neonatal hyperbilirubinemia by limiting bilirubin uptake (7). The rs2306283 (A388G) and rs4149056 (T521C) polymorphisms are associated with a diminished transporter activity (8), but their role in neonatal jaundice is controversial $(8,9)$. Recently, in a genomewide association study, two polymorphisms of another solute carrier organic anion transporter SLCO1B3 gene (rs17680137 $\mathrm{C}>\mathrm{G}$ and rs2117032 $\mathrm{C}>\mathrm{T}$ ) were observed to have a strong association with bilirubin levels and to contribute to idiopathic mild unconjugated hyperbilirubinemia in healthy adults (10).

The aim of this work was to evaluate the influence of the polymorphisms of UGT1A1, SLCO1B1, and SLCO1B3 genes as a contributive cause of severe neonatal hyperbilirubinemia.

\section{RESULTS}

A total of 414 neonates were enrolled in the study, comprising 167 hyperbilirubinemic infants and 247 control subjects. Of the 414,386 completed the study. The DNA extraction was not performed on 20 of the samples because of inadequate material (10 samples in both groups) and 8 samples failed to amplify

\footnotetext{
'Postgraduate Program in Child and Adolescent Health, Universidade Federal do Rio Grande do Sul, Porto Alegre, Brazil; ${ }^{2}$ Experimental Hepatology Laboratory, Hospital de Clínicas de Porto Alegre, Porto Alegre, Brazil; ${ }^{3}$ Pharmacy School, Universidade Federal do Rio Grande do Sul, Porto Alegre, Brazil; ${ }^{4}$ Gene Therapy Center, Hospital de Clínicas de Porto Alegre, Porto Alegre, Brazil. Correspondence: Ursula Matte (umatte@hcpa.ufrgs.br) 
for the UGT1A1 polymorphism. The bilirubin measurements for the case individuals and their distribution according to the American Association of Pediatrics Guidelines for the Management of Hyperbilirubinemia in newborn infants greater than 35 wk gestational age(2) are shown in Figure 1.

The demographic and clinical data for the infants enrolled in the study are shown in Table 1 . The male gender and $\mathrm{ABO}$ incompatibility were more common among the hyperbilirubinemic patients. The mean birth weight was $3,217 \pm 460 \mathrm{~g}$ in the control group and $3,099 \pm 504 \mathrm{~g}$ in the case group $(P=0.014)$. The gestational age also differed between the groups with $39.5 \pm 1.3 \mathrm{wk}$ vs. $38.1 \pm 1.7 \mathrm{wk}(P$ $<0.001)$ for the control and case groups, respectively. An analysis of the frequency of premature newborns in each group revealed that $74(44.3 \%)$ of jaundiced babies were of $<38$ wk gestational age as compared with the $29(11.7 \%)$ control group babies $(P<0.001)$. For the babies in the case group, the median duration of phototherapy time was $2 \mathrm{~d}$, with a median intensive-care unit stay of $3 \mathrm{~d}$.

A glucose-6-phosphate dehydrogenase (G6PD) deficiency was detected in 21 individuals. Among these, none had the Mediterranean mutation, 13 were hemi- or homozygous for the African mutation ( 7 in the case group), 1 was heterozygous for the African mutation and 7 individuals had no mutation ( 2 in the control group). The mean enzyme activity of the deficient subjects was $5.5 \pm 2.0 \mathrm{U} / \mathrm{gHb}$ as compared with that of $17.8 \pm 5.4 \mathrm{U} / \mathrm{gHb}(P<0.001)$ for the nondeficient subjects.

The allelic frequency of the UGT1A1 polymorphism differed between the two groups (Table 2). The $\mathrm{TA}_{5}$ allele was more frequent in the control group $(P=0.04)$, but the genotypic frequency for UGT1A1 did not differ between the groups. The genotypes

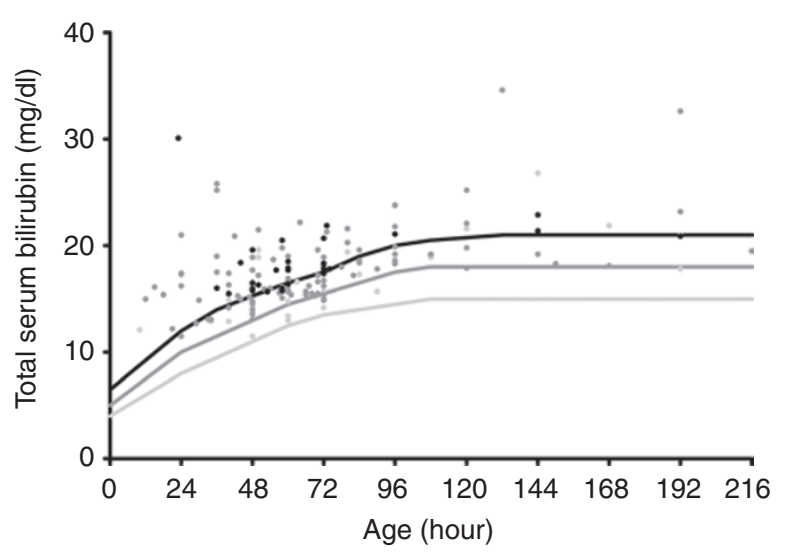

Figure 1. Total serum bilirubin levels vs. age in hours for case subjects, who were hospitalized for phototherapy according to the American Association of Pediatrics guidelines. The lines represent the 95th percentile, above which infants most likely developed neurological damage due to bilirubin toxicity. Black line: infants at minor risk (38 wk or more of gestational age (GA) without risk factors). Dark gray line: infants at medium risk ( 35 to $37 \mathrm{wk}$ of GA without risk factors or $38 \mathrm{wk}$ or more with risk factors). Light gray line: infants at major risk ( 35 to 37 wk of GA with risk factors). Risk factors: hemolytic disease, G6PD deficiency, low albumin, lethargy, temperature instability, and acidosis. G6PD, glucose-6-phosphate dehydrogenase.
$\mathrm{TA}_{5} / \mathrm{TA}_{6}$ and $\mathrm{TA}_{5} / \mathrm{TA}_{7}$ were observed in 11 of the control subjects and only 1 case study individual. The genotypes associated with minor conjugation activity were more frequent in black individuals than in white ones $(22.3 \%$ vs. $10.3 \%, P=0.003)$.

The allelic and genotypic frequencies of the studied polymorphisms from the SLCO genes did not differ among the groups. Homozygosity for at least one of the studied polymorphisms occurred in $53 \%$ of the case subjects and $55 \%$ of the control subjects. Only 2 case subjects were homozygous for all wild-type polymorphisms. The $\mathrm{G}$ allele of rs 2306283 was more frequent in black individuals than in white ones ( 0.63 vs. 0.47 , $P<0.001$ ); however, the T allele of rs 2117032 ( 0.37 vs. $0.52, P<$ 0.001 ) was less frequent in blacks. An analysis of the coinheritance between several of the factors studied revealed that individuals homozygous for the $G$ allele of rs2306283, who were also G6PD deficient, were more frequent in the case subjects than in the control group ( 14.3 vs. $1.7 \%, P=0.039$ ). The haplotype frequencies did not differ between the groups.

Table 1. Demographic and clinical data of control vs. case infants enrolled in this study

\begin{tabular}{|c|c|c|c|}
\hline Factor in study & Control group & Case group & $P$ \\
\hline \multicolumn{4}{|l|}{ Gender $(n=414)$} \\
\hline Male & $122(49.4 \%)$ & $102(61.1 \%)$ & 0.019 \\
\hline Female & $125(50.6 \%)$ & $65(38.9 \%)$ & \\
\hline \multicolumn{4}{|l|}{ Ethnicity $(n=414)$} \\
\hline White & $191(77.3 \%)$ & $122(73.1 \%)$ & NS \\
\hline Black & $56(22.7 \%)$ & $45(26.9 \%)$ & \\
\hline \multicolumn{4}{|c|}{ Size for gestational age $(n=414)$} \\
\hline Appropriate & $192(77.7 \%)$ & $136(81.4 \%)$ & NS \\
\hline Small & $40(16.2 \%)$ & $21(12.6 \%)$ & \\
\hline Large & $15(6.1 \%)$ & $10(6.0 \%)$ & \\
\hline \multicolumn{4}{|c|}{ Birth delivery $(n=414)$} \\
\hline Vaginal & $160(64.8 \%)$ & $113(67.7 \%)$ & NS \\
\hline Cesarean & $87(35.2 \%)$ & $54(32.3 \%)$ & \\
\hline \multicolumn{4}{|c|}{ ABO incompatibility $(n=414)$} \\
\hline Yes & $47(19 \%)$ & $61(36.5 \%)$ & $<0.001$ \\
\hline \multicolumn{4}{|c|}{ Rh ncompatibility $(n=414)$} \\
\hline Yes & $26(10.5 \%)$ & $20(12.0 \%)$ & NS \\
\hline \multicolumn{4}{|c|}{ G6PD deficiency $(n=405)$} \\
\hline Yes & $9(3.7 \%)$ & $12(7.4 \%)$ & NS \\
\hline \multicolumn{4}{|c|}{ Need for reanimation $(n=414)$} \\
\hline Yes & $28(11.3 \%)$ & $12(7.2 \%)$ & NS \\
\hline \multicolumn{4}{|c|}{ Gestational age $(n=414)$} \\
\hline (Mean \pm SD, wk) & $39.5 \pm 1.4$ & $38.1 \pm 1.8$ & $<0.001$ \\
\hline \multicolumn{4}{|c|}{ Birth weight $(n=414)$} \\
\hline$($ Mean $\pm S D, g)$ & $3218 \pm 460$ & $3099 \pm 460$ & 0.014 \\
\hline \multicolumn{4}{|c|}{ Mother's age $(n=411)$} \\
\hline$($ Mean $\pm S D, y)$ & $26.12 \pm 6.8$ & $25.2 \pm 6.5$ & NS \\
\hline \multicolumn{4}{|l|}{ Apgar $5^{\prime}(n=413)$} \\
\hline$($ Mean $\pm S D)$ & $9 \pm 1$ & $9 \pm 1$ & NS \\
\hline
\end{tabular}


A logistic regression was performed to assess the controlling differences in gender, $\mathrm{ABO}$ incompatibility, gestational age, and birth weight. Only differences in the $\mathrm{ABO}$ incompatibility and gestational age remained in the model. Moreover,

Table 2. Allelic, genotypic, and haplotype frequencies of the polymorphisms in UGT1A1, SLCO1B1, and SLCO1B3 genes in control and case groups

\begin{tabular}{|c|c|c|c|}
\hline Factor in study & Control group & Case group & $P$ \\
\hline \multicolumn{4}{|l|}{ UGT1A1 $(n=386)$} \\
\hline \multicolumn{4}{|l|}{ rs8175347 } \\
\hline $\mathrm{TA}_{5}$ & 0.02 & 0.003 & \multirow[t]{4}{*}{$0.0417^{\mathrm{a}}$} \\
\hline $\mathrm{TA}_{6}$ & 0.60 & 0.67 & \\
\hline $\mathrm{TA}_{7}$ & 0.36 & 0.31 & \\
\hline $\mathrm{TA}_{8}$ & 0.01 & 0.01 & \\
\hline $\begin{array}{l}\mathrm{TA}_{6} / \mathrm{TA}_{8^{8}} \mathrm{TA}_{7} / \mathrm{TA}_{7} \text {, and } \\
\mathrm{TA}_{7} / \mathrm{TA}_{8} \text { genotypes }\end{array}$ & $35(14.9 \%)$ & $16(10.5 \%)$ & NS \\
\hline \multicolumn{4}{|l|}{ SLCO1B1 $(n=394)$} \\
\hline \multicolumn{4}{|l|}{ rs4149056 } \\
\hline Callele & 0.13 & 0.11 & NS \\
\hline TT genotype & 179 (75.5\%) & $122(77.7 \%)$ & \multirow[t]{3}{*}{ NS } \\
\hline TC genotype & $55(23.2 \%)$ & $34(21.7 \%)$ & \\
\hline CC genotype & $3(1.3 \%)$ & $1(0.6 \%)$ & \\
\hline \multicolumn{4}{|l|}{ rs2306283 } \\
\hline Gallele & 0.50 & 0.52 & NS \\
\hline AA genotype & $56(23.6 \%)$ & $37(23.6 \%)$ & \multirow[t]{3}{*}{ NS } \\
\hline AG genotype & $123(52.0 \%)$ & $78(49.7 \%)$ & \\
\hline GG genotype & $58(24.5 \%)$ & $42(26.8 \%)$ & \\
\hline \multicolumn{4}{|l|}{$\operatorname{SLCO1B3}(n=394)$} \\
\hline \multicolumn{4}{|l|}{ rs2117032 } \\
\hline Tallele & 0.50 & 0.46 & NS \\
\hline CC genotype & $58(24.5 \%)$ & $50(31.8 \%)$ & \multirow[t]{3}{*}{ NS } \\
\hline CT genotype & 121 (51.1\%) & 69 (43.9\%) & \\
\hline TT genotype & $58(24.5 \%)$ & $38(24.2 \%)$ & \\
\hline \multicolumn{4}{|l|}{ rs17680137 } \\
\hline Gallele & 0.11 & 0.12 & NS \\
\hline CC genotype & 187 (78.9\%) & $121(77.1 \%)$ & \multirow[t]{3}{*}{ NS } \\
\hline CG genotype & $49(20.7 \%)$ & $34(21.7 \%)$ & \\
\hline GG genotype & $1(0.4 \%)$ & $2(1.3 \%)$ & \\
\hline \multicolumn{4}{|l|}{ Haplotypes } \\
\hline \multicolumn{4}{|c|}{ (rs4149056, rs2306283, rs2117032, and rs17680137) } \\
\hline TGCC & $148(31.2 \%)$ & $102(32.5 \%)$ & NS \\
\hline TGCG & $6(1.3 \%)$ & $7(2.2 \%)$ & \\
\hline TGTC & $34(7.2 \%)$ & $23(7.3 \%)$ & \\
\hline TACC & $44(9.3 \%)$ & $35(11.1 \%)$ & \\
\hline TATC & $181(38.2 \%)$ & $110(35.0 \%)$ & \\
\hline CGCC & $45(9.5 \%)$ & $28(8.9 \%)$ & \\
\hline CATC & $12(2.5 \%)$ & $5(1.6 \%)$ & \\
\hline Other ${ }^{b}$ & $4(0.8 \%)$ & $4(1.2 \%)$ & \\
\hline
\end{tabular}

${ }^{a}$ Difference in Fisher's exact test is accounted for TA $A_{5}$ allele.

bOther haplotypes had frequencies less than $1 \%$. the $\mathrm{T}$ allele of rs2117032 seemed to confer protection against hyperbilirubinemia among those who did not present $\mathrm{ABO}$ incompatibility (Table 3).

\section{DISCUSSION}

We studied 414 newborns with and without indication of phototherapy born in South Brazil. Among the well-known risk factors, the only statistical differences between the control and case groups were the $\mathrm{ABO}$ incompatibility, male gender, gestational age, and birth weight. In the multivariate analysis, only the $\mathrm{ABO}$ incompatibility and gestational age remained in the model, showing the large impact of these two variables in hyperbilirubinemia. Although the mean gestational ages of the control and case groups of term neonates were 38.1 and $39.5 \mathrm{wk}$, respectively, the control group showed a remarkably higher frequency of premature newborns; this result is consistent with the data published by Mezzacappa et al.(11). In addition, neonates born before $39 \mathrm{wk}$ require neonatal intensive care and have increased rates of neonatal and infant morbidity and mortality (12).

Our study did not show differences in G6PD deficiency between the groups, although Prachukthum et al. (13) and Wong et al. (14) reported that G6PD deficiency was higher among the patient infants than in the control group. Although the frequency of G6PD deficiency in the study group was almost twice that of the controls (7.4 vs. 3.7\%), it did not reach statistical difference, probably due to the small sample size. The mutations studied for G6PD are the most frequent in our state (15), and the overall prevalence of the deficiency in our sample (5.2\%) is consistent with the $7.8 \%$ previously described in our population (16-19).

Recently, great attention has been given to genetic factors as a contributing cause of neonatal hyperbilirubinemia, and several studies attempted to determine the mechanisms involved in such manifestations $(3,20,21)$. Several studies have failed to demonstrate the relationship between jaundice and the rs8175347 polymorphism of UGT1A1 $(3,11,20)$. Our study presented a higher frequency of the $\mathrm{TA}_{5}$ allele among the control subjects, and this allele is associated with an increase in UGT1A1 expression (22). The statistical difference diminishes when the genotypic frequencies are compared; however, genotypes carrying the $\mathrm{TA}_{5}$ allele were more frequent among the control subjects. The frequencies for UGT1A1 polymorphism observed in our study (23) are consistent with those described in Brazil by Mezzacappa et al.(11).

We did not find any differences in the distribution of the polymorphisms from SLCO1B1. In a Brazilian study of lopinavir and ritonavir in HIV-infected men, similar frequencies of rs 2306283

Table 3. Variables that remained in the logistic regression model

\begin{tabular}{lcc}
\hline Factor in study & OR $(95 \% \mathrm{Cl})$ & $P$ \\
\hline ABO incompatibility & $3.27(1.95-5.50)$ & $<0.001$ \\
Gestational age (for a week increase) & $0.56(0.48-0.66)$ & $<0.001$ \\
Tallele at rs2117032 & $0.57(0.34-0.94)$ & 0.0027 \\
\hline Cl, confidence interval; OR, odds ratio. & &
\end{tabular}


and rs4149056 polymorphisms were observed (24). In 2004, Huang et al.(20) reported that the variant allele of rs2306283 was more frequent among hyperbilirubinemic infants (Odds ratio, $\mathrm{OR}=2.01)$, although these results were not confirmed $(3,13,14)$. Zhang et al. (21), however, showed that infants with the A allele of rs2306283 had higher bilirubin levels when compared with homozygous GG infants. Zhang et al.(21) also showed that the homozygosity for the wild-type allele of rs4149056 was more frequent among hyperbilirubinemic newborns than controls; however, this polymorphism is frequently reported as a diminishing transport activity of OATP1B1 $(8,25)$. Similar to the polymorphisms of SLCO1B1, those of SLCO1B3 did not present statistical differences in the univariate analysis, while we found by using multivariate analysis that the T allele of rs 2117032 could be a protective factor for hyperbilirubinemia. Its frequency is different only when comparing those who do not have ABO incompatibility, showing that $\mathrm{ABO}$ incompatibility could outweigh the modest effect of this polymorphism. Recently, Sanna et al.(10) reported that the C allele of rs17680137 and the T allele of rs2117032 in a genome-wide association analysis were responsible, along with $U G T 1 A 1$ and $G 6 P D$, for the strong association with bilirubin levels in healthy individuals from Sardinia. Kang et al. (26) did not observe any association of these same polymorphisms with bilirubin levels in a Korean sample. For instance, although Cui et al. inferred that SLCO1B1 could be the hepatic transporter for bilirubin (7), Wang et al. (27) concluded the unlikelihood of this function, and Zucker et al. (28) suggested that bilirubin uptake could occur through passive diffusion.

Watchko et al. (3) reported that G6PD-deficient infants who were homozygous for the G allele of rs2306283 were more common in the icteric group as compared with controls $(87.5 \%$ vs. $20 \%, P=0.015)$, respectively. The frequencies reported in our work were $11.1 \%$ in the control group and $50.0 \%$ in the case group. This difference was not statistically significant, perhaps due to the small numbers in each group ( 9 and 12, respectively). However, when the opposite was examined (individuals who were homozygous for $\mathrm{G}$ allele of rs2306283 and who were also G6PD deficient (14.3 vs. $1.7 \%)$ ), a difference was observed ( $P$ $=0.039$ ). Of note, our study presented similar frequencies for the G6PD deficiency in both groups, and the frequencies of the individuals carrying the variant allele of rs2306283 were higher than the ones described by Wathcko et al. (3). Because the G allele is more frequent among blacks and our sample had higher prevalence of black newborns, the difference between the case and control groups could be missed. However, although the frequencies observed for the polymorphisms were similar to those described in the literature for blacks and whites, visual estimation is not an accurate method of defining ethnicity, and an ancestral molecular analysis would work better because we received a great African genome ancestry (29). Recently, Sortica et al. (30) described similar frequencies of the G allele of rs2306283 in white $(48.9 \%)$ and black (64.8\%) individuals from South Brazil who were ethnically classified by self-identification.

Our study is limited by the use of the need for phototherapy as criteria, which is not a strong discriminator to identify differences of genetic variability. This was the first report of the $\mathrm{C}$ allele of rs21170132 polymorphism in neonatal hyperbilirubinemia, and the possibility of its protection against severe jaundice should be further studied. Frequently, the studied polymorphisms present controversial effects in studies and our results demonstrate that they do not have the power to modulate neonatal jaundice. Neonatal jaundice is an excellent example of an intricate manifestation where the usual studied clinical factors alone cannot provide the real cause. Genetic variation is primarily responsible for this condition; however, the mechanisms involved in the association of different polymorphisms and environmental factors have yet to be explained. In addition to the UGT1A1 and SLCO family, other genes involved in the bilirubin pathway (heme oxygenase and biliverdin reductase) should be explored, as well as other environmental factors, such as newborns of HIV-positive mothers using protease inhibitors (31). Both UGT1A1 and SLCO polymorphisms are well studied in pharmacokinetics of drugs $(22,25)$, but their role in neonatal jaundice is still controversial and this matter deserves further consideration.

\section{METHODS}

\section{Subject Enrollment}

This case-controlled study involved newborns of $>35 \mathrm{wk}$ of gestational age and 2,000 g in weight admitted between March and December 2007 to the Neonatal Unit of the Hospital de Clínicas de Porto Alegre, Brazil. The jaundiced babies were assessed using a transcutaneous bilirubinometer (Minolta; Konica Minolta Sensing, Osaka, Japan ). The serum dosage was measured when bilirubin levels were increased, as determined by the diazotization method. The case subjects were infants with total serum bilirubin levels that had indications for phototherapy in accordance with the guidelines of the American Association of Pediatrics (2), whereas the control subjects did not show signs for phototherapy according to visual or laboratory evaluation. The exclusion criteria were based on the following observations-sepsis or infection, cephalohematoma, high levels of conjugated bilirubin, polycythemia, and large ecchymosis. In addition, infants who were administered drugs that could cause the inhibition of glucuronidation were also excluded. The newborns were subjectively classified as black or white based on the skin color and facial features of the parent. All subjects were evaluated until discharge and subsequently evaluated by a trough chart to check the emergence of new outcomes. The Research Ethics Committee at the hospital approved this project, and parental consent was obtained for all infants who participated in this study.

\section{G6PD Enzyme Quantification}

The G6PD Deficiency Neonatal Screening Test Kit (Interscientific, Hollywood, FL ) was used for the quantitative measurement of G6PD activity in peripheral blood. The samples were normalized to their hemoglobin content and then compared with the reference samples (supplied by Interscientific). A cutoff value of $8 \mathrm{U} / \mathrm{g} \mathrm{Hb}$ was used to determine the enzyme deficiency (32).

\section{Molecular Analysis}

The genomic DNA was extracted from $2 \mathrm{ml}$ of cord blood as described (33). The specific mutations of G6PD, UGT1A1, SLCO1B1, and $S L C O 1 B 3$ were analyzed as described below.

The coding region of the G6PD gene, encompassing the African (G202A and A376G) and Mediterranean mutations (C563T), was analyzed by PCR of exons 6,4 , and 5 and posterior restriction fragment-length polymorphism for each mutation $(34,35)$.

The rs8175347 polymorphism was identified by PCR using a FAM-labeled sense primer and analyzed by capillary electrophoresis through the GeneMapper program (ABI, CA ) (23). 
The polymorphisms rs4149056 and rs2306283 from the SLCO1B1 gene and rs17680137 and rs2117032 from the SLCO1B3 gene were identified using hydrolysis probes (TaqMan Assays; ABI), IDs: C_30633906_10, C_1901697_20, C_25766725_10, and C_2809241_10, respectively. A total of $15 \mathrm{ng}$ of DNA was used in a final reaction volume of $12.5 \mu \mathrm{l}$ for real-time PCR on a Stratagene Thermocycler (GE) and analyzed through Mx3000P software (GE).

\section{Statistical Analysis}

For the categorical data, the $\chi^{2}$ and Fisher exact tests were performed where appropriate, and the residuals were adjusted when necessary. The ORs and 95\% confidence intervals were estimated for severe hyperbilirubinemia risk factors using multivariate logistic regression models. The numeric variables were analyzed using the Student's $t$ test. The haplotypes for the four polymorphisms of the SLCO1B1 and SLCO1B3 genes were statistically reconstructed using the PHASE program, version 2.1, which implements a Bayesian statistical method for reconstructing haplotypes from genotype data $(36,37)$. The data were considered to be significant when $P$ was less than 0.05 .

\section{ACKNOWLEDGMENTS}

The authors thank Mara Hutz from the Genetics Department of Universidade Federal do Rio Grande do Sul for critical suggestions in the data analysis.

\section{STATEMENT OF FINANCIAL SUPPORT}

The authors thank Coordenação de Aperfeiçoamento de Pessoal de Nível Superior (CAPES), Conselho Nacional de Desenvolvimento Científico e Tecnológico (CNPq), and Fundo de Incentivo à Pesquisa e Eventos do Hospital de Clínicas de Porto Alegre (FIPE-HCPA) for their financial support.

\section{REFERENCES}

1. Bhutani VK, Gourley GR, Adler S, Kreamer B, Dalin C, Johnson LH. Noninvasive measurement of total serum bilirubin in a multiracial predischarge newborn population to assess the risk of severe hyperbilirubinemia. Pediatrics 2000;106:E17.

2. AAP. Management of hyperbilirubinemia in the newborn infant 35 or more weeks of gestation. Pediatrics 2004;114:297-316.

3. Watchko JF, Lin Z, Clark RH, Kelleher AS, Walker MW, Spitzer AR; Pediatrix Hyperbilirubinemia Study Group. Complex multifactorial nature of significant hyperbilirubinemia in neonates. Pediatrics 2009;124:e868-77.

4. Bosma P, Chowdhury JR, Jansen PH. Genetic inheritance of Gilbert's syndrome. Lancet 1995;346:314-5.

5. Maisels MJ. Jaundice. In: Avery GB, MacDonald MG, Seshia MMK, Mullet MD, eds. Avery's Neonatology: Pathophysiology \& Management of the Newborn. Philadelphia: Lippincott Williams \& Wilkins, 2005:768-846.

6. Beutler E, Gelbart T, Demina A. Racial variability in the UDP-glucuronosyltransferase 1 (UGT1A1) promoter: a balanced polymorphism for regulation of bilirubin metabolism? Proc Natl Acad Sci USA 1998;95:8170-4.

7. Cui Y, König J, Leier I, Buchholz U, Keppler D. Hepatic uptake of bilirubin and its conjugates by the human organic anion transporter SLC21A6. J Biol Chem 2001;276:9626-30.

8. Kalliokoski A, Niemi M. Impact of OATP transporters on pharmacokinetics. Br J Pharmacol 2009;158:693-705.

9. Watchko JF, Lin Z. Exploring the genetic architecture of neonatal hyperbilirubinemia. Semin Fetal Neonatal Med 2010;15:169-75.

10. Sanna S, Busonero F, Maschio A, et al. Common variants in the SLCO1B3 locus are associated with bilirubin levels and unconjugated hyperbilirubinemia. Hum Mol Genet 2009;18:2711-8.

11. Mezzacappa MA, Facchini FP, Pinto AC, et al. Clinical and genetic risk factors for moderate hyperbilirubinemia in Brazilian newborn infants. J Perinatol 2010;30:819-26.

12. Donovan EF, Lannon C, Bailit J, Rose B, Iams JD, Byczkowski T; Ohio Perinatal Quality Collaborative Writing Committee. A statewide initiative to reduce inappropriate scheduled births at 36(0/7)-38(6/7) weeks' gestation. Am J Obstet Gynecol 2010;202:243.e1-8.

13. Prachukthum S, Nunnarumit P, Pienvichit $P$, et al. Genetic polymorphisms in Thai neonates with hyperbilirubinemia. Acta Paediatr 2009;98:1106-10.
14. Wong FL, Boo NY, Ainoon O, Wang MK. Variants of organic anion transporter polypeptide 2 gene are not risk factors associated with severe neonatal hyperbilirubinemia. Malays J Pathol 2009;31:99-104.

15. Castro SM, Weber R, Matte U, Giugliani R. Molecular characterization of glucose-6-phosphate dehydrogenase deficiency in patients from the southern Brazilian city of Porto Alegre, RS. Genet Mol Biol 2007;30:10-3.

16. Castro S, Weber R, Dadalt V, Tavares V, Giugliani R. Prevalence of G6PD deficiency in newborns in the south of Brazil. J Med Screen 2006;13:85-6.

17. Saad ST, Salles TS, Carvalho MH, Costa FF. Molecular characterization of glucose-6-phosphate dehydrogenase deficiency in Brazil. Hum Hered 1997;47:17-21.

18. Compri MB, Saad ST, Ramalho AS. [Genetico-epidemiological and molecular investigation of G-6-PD deficiency in a Brazilian community]. Cad Saude Publica 2000;16:335-42.

19. Weimer TA, Salzano FM, Westwood B, Beutler E. Molecular characterization of glucose-6-phosphate dehydrogenase variants from Brazil. Hum Biol 1993;65:41-7.

20. Huang MJ, Kua KE, Teng HC, Tang KS, Weng HW, Huang CS. Risk factors for severe hyperbilirubinemia in neonates. Pediatr Res 2004;56:682-9.

21. Zhang HX, Zhao X, Yang Z, et al. [OATP 1B1 T521C/A388G is an important polymorphism gene related to neonatal hyperbilirubinemia]. Zhonghua Er Ke Za Zhi 2010;48:650-5.

22. Strassburg CP, Lankisch TO, Manns MP, Ehmer U. Family 1 uridine-5'diphosphate glucuronosyltransferases (UGT1A): from Gilbert's syndrome to genetic organization and variability. Arch Toxicol 2008;82:415-33.

23. Carvalho CG, Castro SM, Santin AP, de Azevedo LA, Pereira ML, Giugliani R. Polymorphic variants of UGT1A1 in neonatal jaundice in southern Brazil. J Trop Pediatr 2010;56:366-7.

24. Kohlrausch FB, de Cássia Estrela R, Barroso PF, Suarez-Kurtz G. The impact of SLCO1B1 polymorphisms on the plasma concentration of lopinavir and ritonavir in HIV-infected men. Br J Clin Pharmacol 2010;69:95-8.

25. Niemi M. Role of OATP transporters in the disposition of drugs. Pharmacogenomics 2007;8:787-802.

26. Kang TW, Kim HJ, Ju H, et al. Genome-wide association of serum bilirubin levels in Korean population. Hum Mol Genet 2010;19:3672-8.

27. Wang P, Kim RB, Chowdhury JR, Wolkoff AW. The human organic anion transport protein SLC21A6 is not sufficient for bilirubin transport. J Biol Chem 2003;278:20695-9.

28. Zucker SD, Goessling W, Hoppin AG. Unconjugated bilirubin exhibits spontaneous diffusion through model lipid bilayers and native hepatocyte membranes. J Biol Chem 1999;274:10852-62.

29. Pimenta JR, Zuccherato LW, Debes AA, et al. Color and genomic ancestry in Brazilians: a study with forensic microsatellites. Hum Hered 2006;62:190-5.

30. Sortica VD, Ojopi EB, Genro JP, et al. Influence of Genomic Ancestry on the Distribution of SLCO1B1, SLCO1B3 and ABCB1 Gene Polymorphisms among Brazilians. Basic Clin Pharmacol Toxicol 2012;110:460-8.

31. Mandelbrot L, Mazy F, Floch-Tudal C, et al. Atazanavir in pregnancy: impact on neonatal hyperbilirubinemia. Eur J Obstet Gynecol Reprod Biol 2011;157:18-21.

32. Castro SM, Weber R, Matte U, et al. The use of LR values to check the best fit of cut-off values in G6PD deficient cases. Clin Biochem 2007;40:496-8.

33. Lahiri DK, Nurnberger JI Jr. A rapid non-enzymatic method for the preparation of HMW DNA from blood for RFLP studies. Nucleic Acids Res 1991;19:5444.

34. Cittadella R, Civitelli D, Manna I, et al. Genetic heterogeneity of glucose-6phosphate dehydrogenase deficiency in south-east Sicily. Ann Hum Genet 1997;61(Pt 3):229-34.

35. Bouanga JC, Mouélé R, Préhu C, Wajcman H, Feingold J, Galactéros F. Glucose-6-phosphate dehydrogenase deficiency and homozygous sickle cell disease in Congo. Hum Hered 1998;48:192-7.

36. Stephens M, Smith NJ, Donnelly P. A new statistical method for haplotype reconstruction from population data. Am J Hum Genet 2001;68:978-89.

37. Stephens M, Scheet P. Accounting for decay of linkage disequilibrium in haplotype inference and missing-data imputation. Am J Hum Genet 2005;76:449-62. 